\title{
Locational Marginal Prices Scheme Considering Transmission Congestion and Network Losses
}

\author{
Muhammad Bachtiar Nappu \\ Department of Electrical Engineering, Hasanuddin University, Makassar 90245, South Sulawesi, Indonesia \\ *Corresponding Author: thiar@engineer.com
}

Copyright (C) 2014 Horizon Research Publishing All rights reserved.

\begin{abstract}
This manuscript presents a basic concept of nodal price modeling in a competitive electricity market and some special considerations on its formulation. Nodal prices represented by locational marginal prices (LMP) based settlement strategy is carried out in a deregulated market environment to establish the amount of money received by generation companies from system operator and paid to system operator from customers. In this approach, cost of transmission services is implemented together with LMP which represents energy price, network losses cost, and transmission congestion cost. The results show that the proposed method has a better performance than the use of conventional approach.
\end{abstract}

Keywords Transmission Congestion, Electricity Market, Locational Marginal Prices, Network Losses, Economic Dispatch, Optimal Power Flow, Shift Factor, Nodal Price

\section{Introduction}

In a competitive market environment, bottlenecks in the transmission line will be an obstacle for perfect competition among the market participants. Hence, the operation and planning of transmission network systems should be planned appropriately [1-3]. One obvious drawback of transmission constraint is the congestion problem. Congestion is a result of transmission constraint limiting the network capacity, which imposes the simultaneous power transfer from a set of power transactions.

Other significant issues that should also be addressed in transmission management are network usage tariff and losses $[4,5]$. Transmission usage tariff is defined as embedded-cost, while [6] classified it as use-of-transmission-system charge. This is to convert stranded costs and O\&M costs into transmission charge cost, which refers to the previous capital cost acquired in the transmission infrastructure development and maintenance [7-10]. The last aspect in transmission management is the cost of losses in the network. Although the impact of losses may be small compared to other potential sources of market inefficiency, this should also be taken into account.

Above all, transmission congestion issue remains the central problem in the new electricity structure [11-15]. Independent system operator (ISO) usually observes the transactions, controls the state of the system and takes an important role in handling the network congestion management. Market operator is responsible to alleviate network congestion to maintain the security and efficiency of power system operation in order to ensure all market participants have the same rights to access transmission system without any discrimination $[2,16]$.

Therefore, the author in this paper introduces a scheme for incremental cost-based energy pricing model to deal with congestion including losses and transmission usage tariff, but simplify the method and have acceptable transparency so that it may correctly send an economic signal to the market participants. In this manuscript, a new scheme is presented to briefly review the main idea behind the LMP calculation, and further discuss the techniques used to incorporate transmission usage tariff into the model. This would be a comprehensive approach in which pricing of transmission services is implemented together with short-term nodal pricing, which is representing energy price, network losses cost, and transmission congestion cost.

\section{Proposed Method}

Shift factor (S) methodology is employed in order to perform congestion-based nodal price model through optimal power flow approach. It is used with the intention to maintain the linearity and superposition features of the locational marginal price (LMP) model while still able to account for both congestion and losses cost [17]. The shift factor helps to determine the power flow over a given transmission line from the source node (generation) to the sink node (load). It is characterized by four attributes, namely; a reference node, a particular node, a particular line with reference direction, and the value of the shift factor. In other words, the shift factor can be seen as the fraction of transaction amount in line $l$ due to injection change at the node $i$. 


$$
S=\frac{\Delta \text { flow in line } l}{\Delta \text { injection at nodei }}
$$

Shift factor values will depend on network topology and line impedance. Once these two variables change, the value of shift factor will change as well.

Meanwhile dispatch model discussed in this paper encompasses energy price, transmission congestion revenue, and transmission losses cost. Embedded cost in terms of transmission usage tariff is also added into this formulation. Market operators use different approaches to account this tariff, such as: postage-stamp method, contract path method, MW-mile method, or counter-flow method [18].

So far, pricing for transmission services using such methods above are still separately accounted from energy market price calculation. With the intention of having an efficient, transparent, and effective pricing due to transmission network usage services, LMP models under this scheme will be formulated by taking into account the tariff for transmission usage as well.

By incorporating this component, the scheme is expected to simplify the method and to have acceptable transparency so that this may send economic signal correctly to the market participants [19-21]. Accordingly, formulation for this model will be as follow;

Total transmission usage tariff is written as

$$
T_{m}\left(P_{G_{i}}\right)=\alpha_{m} . \text { flow }_{m}
$$

The objective function is to minimize the total social cost and transmission usage tariff to decide the power supply and required demand.

$$
\begin{aligned}
\operatorname{Min} & \sum_{m=1}^{M} \alpha_{m} \mid \text { flow }_{m}\left(P_{G_{i}}\right) \mid+\sum_{i=1}^{n_{G}}\left[a_{i} P_{G_{i}}^{2}+b_{i} P_{G_{i}}+c_{i}\right] \\
& -\sum_{i=1}^{n_{D}}\left[d_{i} P_{D_{i}}^{2}+e_{i} P_{D_{i}}+f_{i}\right]
\end{aligned}
$$

Subject to the following constraints

$$
\begin{aligned}
& \sum_{i} P_{G_{i}}-P_{\text {loss }}\left(P_{G_{i}}\right)=\sum_{j} P_{D_{j}} \\
& P_{\mathrm{G} i}{ }^{\text {min }} \leq P_{\mathrm{G} i} \leq P_{\mathrm{G} i}{ }^{\text {max }} \\
& P_{\mathrm{D} j}{ }^{m i n} \leq P_{\mathrm{D} j} \leq P_{\mathrm{D} j}{ }^{\text {max }} \\
& \text { flow }_{m}{ }^{\text {min }} \leq \text { flow }_{m} \leq \text { flow }_{m}{ }^{\text {max }}
\end{aligned}
$$

With referring to the objective function and the constraints, Lagrange function is then formed using Lagrangian multipliers. These multipliers are referred to dual prices or shadow prices.

$$
\begin{aligned}
& L\left(P_{D_{i}}, P_{G_{i}}, \lambda_{i}, \mu_{i}\right)=\sum_{m}^{M} T_{m}\left(P_{G_{i}}\right)+\sum_{i=1}^{n_{G}} C_{i}\left(P_{G_{i}}\right)-\sum_{i=1}^{n_{0}} B_{i}\left(P_{D_{i}}\right) \\
& +\lambda_{i}\left(\sum_{j} P_{D_{j}}-\sum_{i} P_{G_{i}}-P_{l o s s}\left(P_{G_{i}}\right)\right) \\
& -\sum \mu_{\text {min, }, j, j}\left(P_{D_{j}}-P_{D_{j}}{ }^{\min }\right)+\sum \mu_{\max , D, j}\left(P_{D_{j}}-P_{D_{j}}{ }^{\max }\right) \\
& -\sum \mu_{\min , G, I}\left(P_{G I}-P_{G_{I}}{ }^{\min }\right)+\sum \mu_{\max , G, I}\left(P_{G I}-P_{G_{I}}{ }^{\max }\right) \\
& -\sum_{m} \mu_{\text {min, ffow }, m}\left(\text { flow }_{m}-\text { flow }_{m}{ }^{\min }\right)+\sum_{m} \mu_{\max , f l o w, m}\left(\text { flow }_{m}-\text { flow }_{m}{ }^{\text {max }}\right)
\end{aligned}
$$

In order to obtain optimum solution for the calculation of congestion cost and locational marginal prices, the first order of Karush-Kuhn-Tucker (KKT) optimal condition should be reached, which is derived from the Lagrange function.

If we assume

$$
\begin{gathered}
G_{\text {loss }}=2 \cdot[S]^{T} \cdot[R] \cdot[S] \\
P_{\text {loss }}\left(P_{G i}\right)=\left(\frac{1}{2}\right) \cdot\left(\begin{array}{l}
{\left[P_{G i}\right]_{1 x i}^{T}\left[A_{G}\right]_{i x i}\left[P_{G i}\right]_{i x 1}-} \\
2 \cdot\left[P_{D j}\right]_{1 x i}^{T}\left[B_{G}\right]_{i x i}\left[P_{D j}\right]_{j x 1}+\left[B_{G}\right]_{i x i}
\end{array}\right)
\end{gathered}
$$

where

$$
\begin{aligned}
& {\left[\mathrm{A}_{\mathrm{G}}\right]=\left[\mathrm{M}_{\mathrm{G}}\right]^{\mathrm{T}} \cdot\left[G_{\text {loss }}\right] \cdot\left[\mathrm{M}_{\mathrm{G}}\right]} \\
& {\left[\mathrm{B}_{\mathrm{G}}\right]=\left[\mathrm{M}_{\mathrm{D}}\right]^{\mathrm{T}} \cdot\left[G_{\text {loss }}\right] \cdot\left[\mathrm{M}_{\mathrm{G}}\right]=\left[\mathrm{M}_{\mathrm{G}}\right]^{\mathrm{T}}\left[G_{\text {loss }}\right]\left[\mathrm{M}_{\mathrm{D}}\right]} \\
& {\left[\mathrm{C}_{\mathrm{G}}\right]=\left[\mathrm{M}_{\mathrm{D}}\right]^{\mathrm{T}} \cdot\left[G_{\text {loss }}\right] \cdot\left[\mathrm{M}_{\mathrm{D}}\right]}
\end{aligned}
$$

After obtaining the first order of Karush-Kuhn-Tucker optimal condition, marginal nodal prices or LMPs for both supplier and consumer nodes may be formulated as follows:

$$
\begin{aligned}
& \rho_{i}=\lambda\left\{1-\sum_{i=1}^{I} G_{l o s s_{n, i^{\prime}}}\left(\sum_{i \in I\left(i^{\prime}\right)} P_{G i}-\sum_{j \in J\left(i^{\prime}\right)} P_{D j}\right)\right\}+\sum_{m} \mu_{\min , f l o w, m} \cdot S_{m, n} \\
& -\sum_{m} \mu_{\text {max }, f l o w, m} \cdot S_{m, n}-\sum_{m} \alpha_{m} \cdot \frac{\text { flow }_{m}\left(P_{G i}\right)}{\mid \text { flow }_{m}\left(P_{G i}\right) \mid} \cdot S_{m, n}
\end{aligned}
$$

The merchandizing surplus (MS) which contains congestion revenue, cost of losses, and transmission usage tariff will be:

$$
\begin{aligned}
M S= & \lambda \cdot P_{l o s s}\left(P_{G i}\right)+\sum_{m} \mu_{\max , \text { flow }, m} . \text { flow }_{m}-\sum_{m} \mu_{\min , \text { flow }, m} . \text { flow }_{m} \\
& +\sum_{m} \alpha_{m} \cdot \mid \text { flow }_{m}\left(P_{G i}\right) \mid
\end{aligned}
$$

\section{Results and Analysis}

The proposed method is implemented with a simple 3-bus system. Some important characteristics are evaluated to describe beneficial features of the proposed method. The system is required to deliver an aggregated load of $800 \mathrm{MW}$. System details consisting of generation and branch profile are given in Table I. Further implementation of the proposed method on an IEEE reliability test system (IEEE-RTS) as well as on different issues can be found at [22-31].

Table 1. 3-Bus System Generator and Branch Details

\begin{tabular}{|c|c|c|c|c|c|c|}
\hline \multicolumn{7}{|c|}{ Generator Profile } \\
\hline & \multicolumn{2}{|c|}{$\begin{array}{c}\mathrm{b}_{\mathrm{i}} \\
(\$ / \mathrm{MWh})\end{array}$} & \multicolumn{2}{c|}{$\begin{array}{c}\mathrm{m}_{\mathrm{i}} \\
\left(\$ / \mathrm{MW}^{2} \mathrm{~h}\right)\end{array}$} & $\begin{array}{c}\operatorname{min~}_{\mathrm{i}} \\
(\mathrm{MW})\end{array}$ & $\begin{array}{c}\operatorname{max~}_{\mathrm{i}} \\
(\mathrm{MW})\end{array}$ \\
\hline $\mathrm{G}_{1}$ & \multicolumn{2}{|c|}{20} & \multicolumn{2}{c|}{0.015} & 150 & 600 \\
\hline $\mathrm{G}_{2}$ & \multicolumn{2}{|c|}{18} & \multicolumn{2}{c|}{0.015} & 50 & 400 \\
\hline \multicolumn{7}{|c|}{ Branch Profile } \\
\hline L1 & 1 & 2 & 0.0134 & 0.1335 & 200 & 2 \\
\hline L2 & 1 & 3 & 0.0067 & 0.0665 & 550 & 1 \\
\hline L3 & 2 & 3 & 0.0084 & 0.1002 & 350 & 1.25 \\
\hline
\end{tabular}


From the simulation, it can be observed that the minimum cost is achieved when node- 2 is selected as the reference node. This option makes an optimal power supply for network losses at $24.00 \mathrm{MW}$, compared to $24.06 \mathrm{MW}$ and 25.53 MW for node- 1 and node-3, respectively.

Although node- 1 and node- 2 tend to have the same network losses supply, selecting node-2 as reference node gives a minimum objective value as well. This is similar to the results of model without adding the embedded cost. However, LMPs obtained under this scheme are now having additional cost; namely transmission usage tariff. As a result, despite all generators' output and total branch losses being similar before and after incorporating the embedded cost, the objective value, cost of losses, and merchandizing surplus are different. The relationship between objective value and merchandizing surplus relatively to the selection of reference node are given in Figures 1 and 2.

It is obvious from simulation results that the most significant finding is that branch flow over transmission line 2-3 becomes un-congested when node- 2 is selected as the reference node. Meanwhile choosing node-1 or node- 3 as reference node or even for all reference nodes under scheme without losses component, line 2-3 is always in binding circumstances. This means transmission congestion is able to be avoided which is in this case by choosing node- 2 as the reference node.

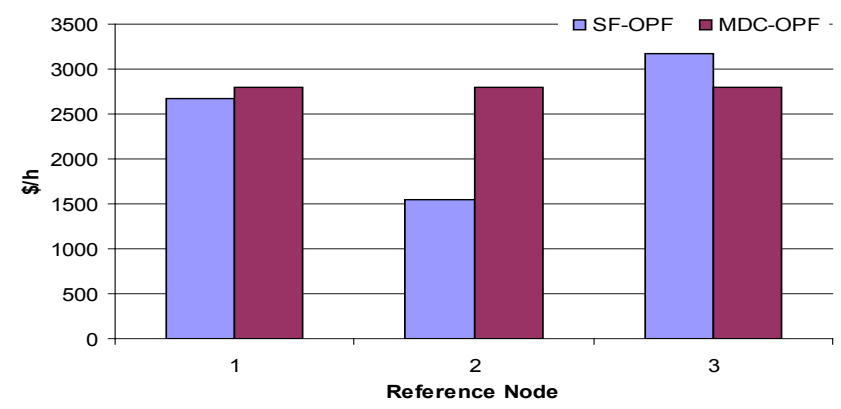

Figure 1. Merchandizing Surplus

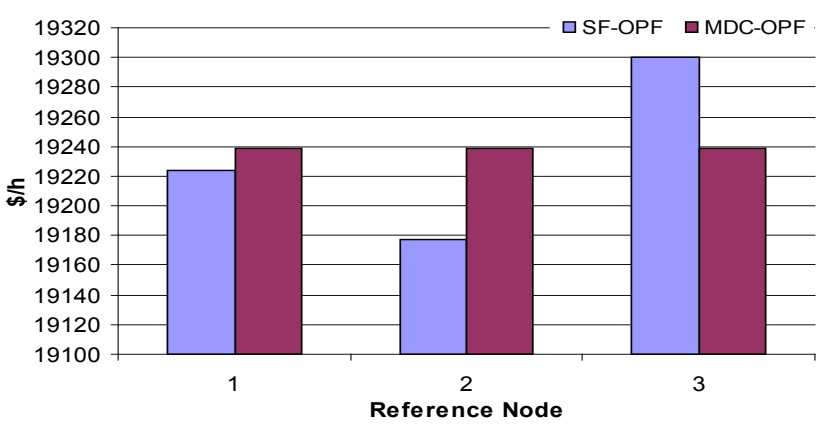

Figure 2. Objective Value

Accordingly, there is no congestion revenue, and merchandizing surplus only contains cost of network losses, which is the lowest cost of losses as well for this scheme. That is why merchandizing surplus and objective value in this option are about half of the value of other selected reference node, as shown in Figures 1-2. Normally, this congestion revenue takes a big portion in performing merchandizing surplus. Illustration about the change of branch flow is shown in Figures 3-7.

In summary, based on all output parameters resulted from the simulations, it is clearly proven that the proposed method shows an improved performance compared to the widely well-known conventional method, DC-OPF.

Findings of this work are supposed to be useful to support developing standard market design in transmission networks, which promotes economic efficiency, lowers delivered energy costs, maintains power system reliability and mitigates exercising market power.

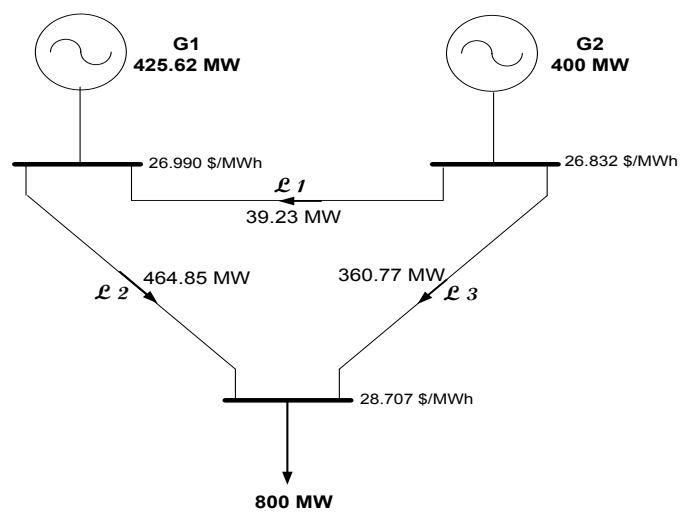

Figure 3. Unconstrained Branch Flow

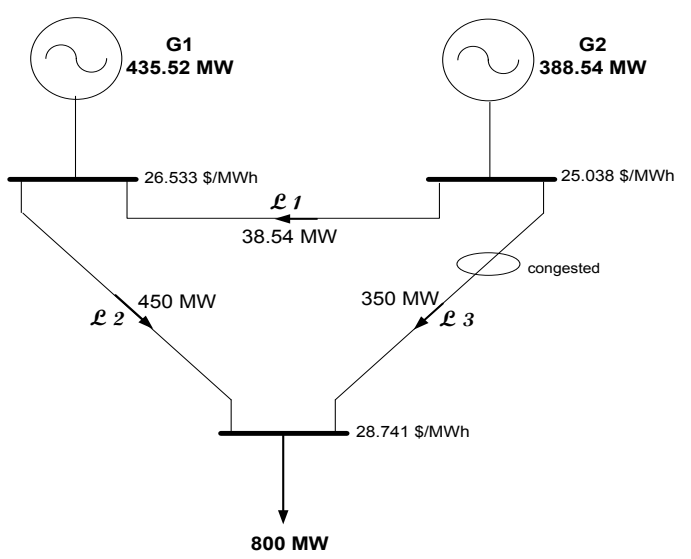

Figure 4. Constrained Branch Flow Using SF-OPF with Ref. Node \#1

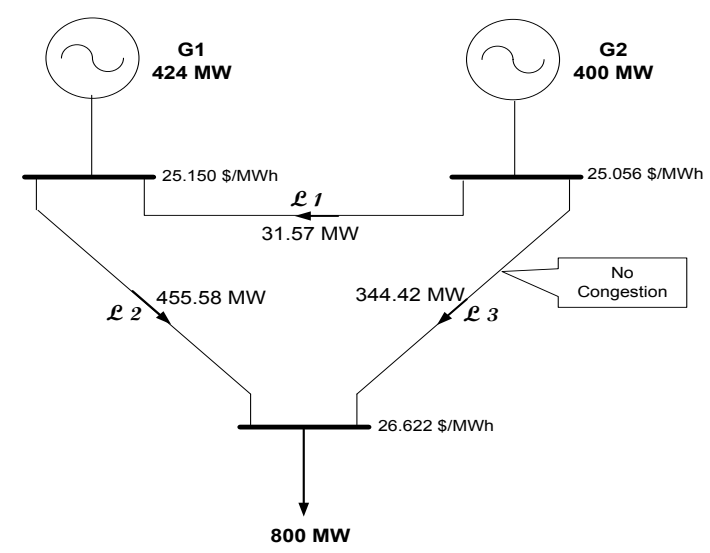

Figure 5. Constrained Branch Flow Using SF-OPF with Ref. Node \#2 


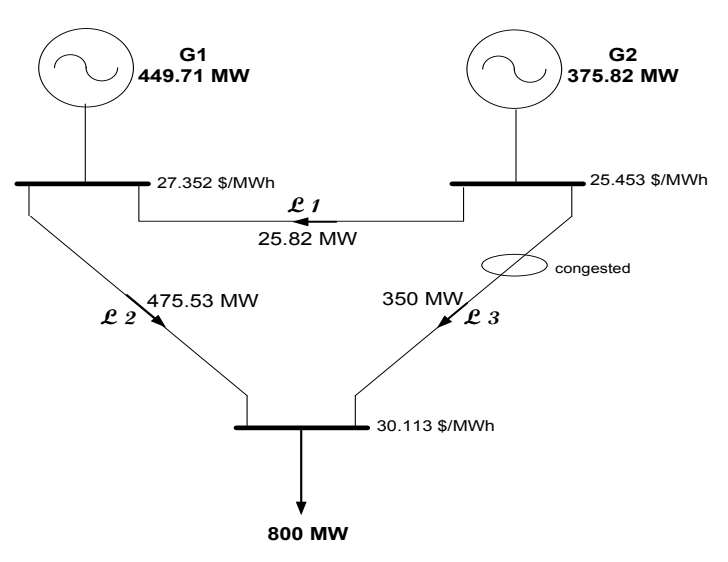

Figure 6. Constrained Branch Flow Using SF-OPF with Ref. Node \#3

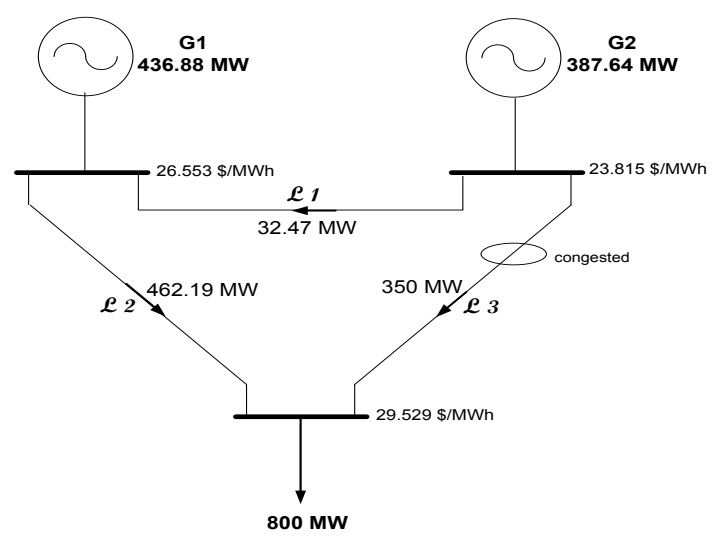

Figure 7. Constrained Branch Flow Using DC-OPF

\section{Conclusions}

There are three significant issues of transmission management that should be properly handled to accomplish open access environment in a competitive electricity market, such as: transmission congestion cost, network losses cost as well as transmission usage tariff. Besides, an effective congestion-based nodal price modeling is the key factor in determining transmission pricing, which could generate economic signal especially as congestion happens.

A comprehensive tool for congestion-based nodal pricing is need to be developed to encourage transparent and competitive price but still be able to address the issues surrounding transmission management.

Therefore, in this paper a new perspective of the impact of market clearing mechanisms on electricity pricing is addressed. An alternative method that makes use of shift factor based optimal power flow is developed as an improvement over traditional DC optimal power flow method. The results show that the proposed method has a better performance than the use of conventional approach.

\section{REFERENCES}

[1] W. W. Hogan, "Independent System Operator: Pricing and Flexibility in A Competitive Electricity Market," John F. Kennedy School of Government, Harvard University, Cambridge, Massachusetts Feb. 1998.

[2] R. D. Tabors and S. Adamson, "Price Discrimination in Organized/Centralized Electric Power Markets," 2006.

[3] G. B. Shrestha and P. A. J. Fonseka, "Congestion-driven transmission expansion in competitive power markets," IEEE Transactions on Power Systems, vol. 19, pp. 1658-1665, 2004.

[4] R. D. Christie, B. F. Wollenberg, and I. Wangensteen, "Transmission management in the deregulated environment," Proceedings of the IEEE, vol. 88, pp. 170-195, 2000.

[5] J. B. Cardell, "Improved Marginal Loss Calculations during Hours of Transmission Congestion," 2005.

[6] A. K. David, "Dispatch methodologies for open access transmission systems," IEEE Transactions on Power Systems, vol. 13, pp. 46-53, 1998.

[7] P. Kaymaz, J. Valenzuela, and C. S. Park, "Transmission Congestion and Competition on Power Generation Expansion," IEEE Transactions on Power Systems, vol. 22, pp. 156-163, 2007.

[8] M. C. Falvo, "An approach for transmission system expansion planning in electricity market," 2006

[9] H. Rudnick, R. Palma, and J. E. Fernandez, "Marginal pricing and supplement cost allocation in transmission open access," IEEE Transactions on Power Systems, vol. 10, pp. 1125-1132, 1995.

[10] I. J. Perez-Arrilaga, F. J. Rubio, J. F. Puerto, J. Arceluz, and J. Marin, "Marginal pricing of transmission services: an analysis of cost recovery," IEEE Transactions on Power Systems, vol. 10, pp. 546-553, 1995.

[11] H. Singh, S. Hao, and A. Papalexopoulos, "Transmission congestion management in competitive electricity markets," IEEE Transactions on Power Systems, vol. 13, pp. 672-680, 1998.

[12] R. S. Fang and A. K. David, "Transmission congestion management in an electricity market," IEEE Transactions on Power Systems, vol. 14, pp. 877-883, 1999.

[13] F. C. Schweppe, M. C. Caramanis, R. D. Tabors, and R. E. Bohn, Spot Pricing of Electricity. Boston: Kluwer Academic Publishers, 1988.

[14] T. W. Gedra, "On transmission congestion and pricing," IEEE Transactions on Power Systems, vol. 14, pp. 241-248, 1999.

[15] J. Cardell, "A Real Time Price Signal for FACTS Devices to Reduce Transmission Congestion," 2007.

[16] D. Shirmohammadi, B. Wollenberg, A. Vojdani, P. Sandrin, M. Pereira, F. Rahimi, T. Schneider, and B. Stott, "Transmission dispatch and congestion management in the emerging energy market structures," IEEE Transactions on Power Systems, vol. 13, pp. 1466-1474, 1998.

[17] California-ISO, "Shift Factors: Methodology and Example," in CAISO Market Operations: [online] Available:, 2008, pp. 
http://www.caiso.com/docs/2004/02/13/2004021316094386 84.pdf.

[18] M. Shahidehpour, H. Yamin, and Z. Li, Market Operations in Electric Power Systems. New York: John Wiley \& Sons, Inc., 2002.

[19] E. D. Farmer, B. J. Cory, and B. L. P. P. Perera, "Optimal pricing of transmission and distribution services in electricity supply," IEE Proceedings-Generation, Transmission and Distribution, vol. 142, pp. 1-8, 1995.

[20] G. Hamoud and I. Bradley, "Assessment of transmission congestion cost and locational marginal pricing in a competitive electricity market," IEEE Transactions on Power Systems, vol. 19, pp. 769-775, 2004.

[21] P. A. J. Fonseka and G. B. Shrestha, "A Study on the Pricing of Network Services," presented at International Conference on Power System Technology, PowerCon, 2006.

[22] M.B. Nappu, T.K. Saha, P.A.J. Fonseka, "Assessment of the Effectiveness of Different Pricing Schemes for Transmission Congestion Management", in The 84th National Electric Energy Society of Australia (EESA) Conference and Exhibition, Brisbane, Australia, 2008.

[23] M. B. Nappu, T. K. Saha, and P. A. J. Fonseka, "Investigation on congestion-based optimal energy price for competitive electricity market," in IEEE International Conference on Sustainable Energy Technologies, Singapore, 24-27 November, 2008, pp. 860-865.
[24] M. B. Nappu and T. K. Saha, "A comprehensive tool for congestion-based nodal price modelling," in IEEE Power \& Energy Society General Meeting (PES-GM), Calgary, Alberta, Canada, 26-30 July, 2009, pp. 1-8.

[25] M. B. Nappu, T. K. Saha, and A. Arief, "Analysis of the influence of transmission congestion on power market based on LMP-lossless model," in 19th Australasian Universities Power Engineering Conference, AUPEC '09, Adelaide, Australia, 2009, pp. 1-6.

[26] M. B. Nappu and T. K. Saha, "Study on Congested Power System in Competitive Electricity Market: A Proposed Methodology," in International Power Engineering Conference, IPEC '10, Singapore, 27-30 October, 2010, pp. 830-835.

[27] M. B. Nappu and T. K. Saha, "Financial withheld-based market power within congested power system," in 21st Australasian Universities Power Engineering Conference, AUPEC '11, Brisbane, Australia, 2011, pp. 1-6.

[28] M. B. Nappu, A. Arief, T. K. Saha, and R. C. Bansal, "Investigation of LMP forecasting for congested power systems," in 22nd Australasian Universities Power Engineering Conference, AUPEC '12, Denpasar, Bali, Indonesia, 2012, pp. 1-6.

[29] M. B. Nappu, R. C. Bansal, and T. K. Saha, "Market power implication on congested power system: A case study of financial withheld strategy," International Journal of Electrical Power \& Energy Systems, Elsevier, vol. 47, pp. 408-415, 2013. 